\title{
Instructor Perspectives of Online VERSUS FACE-TO-FACE EdUCATION AT A Jesuit Institution: Program Factors
}

\author{
Lynn A.Fish and Coral R. Snodgrass
}

Lynn A. Fish and Coral R. Snodgrass both hold the rank of Professor of Management, Canisius College, 2001 Main Street, Buffalo, NY 14208

\begin{abstract}
While instructors are a critical component of the education paradigm, research into instructor perspectives on online education is sparse. The purpose of this phase of a larger study is to explore program factors in instructor perceptions of online versus faceto-face education at a Jesuit, Catholic private University in the northeast. A literature review indicates that demographic, individual instructor and program differences are the salient factors that influence these perceptions. Program factors that this portion of the study addressed includes program difficulty, interaction between students and instructors, interaction between the student and the instructor, cheating and technology preference.
\end{abstract}

Keywords: instructor perceptions, online education, program 
16 The BRC Academy Journal of Education Vol. 7, No. 1

DOI: http://dx.doi.org/10.15239/j.brcacadje.2018.07.01.ja03

\section{LITERATURE REVIEW}

The purpose of this study is to explore differences in instructor perceptions of online verses face-to-face (FTF) instruction. While this isn't the first study to examine these issues, it is clear from a review of the literature that recent literature on this topic is sparse. Recent research highlighted the increase in online education throughout the higher education system (Allen \& Seamen, 2013). In addition, the issues are ever changing. A recent study on instructor attitudes with respect to instructor online presence noted that studies into instructor and student perceptions will continue to evolve as technology evolves (Richardson et al., 2016). In studies of student perceptions of online versus FTF education, gender, age and experience, and academic background have all been shown to yield differing results over time (Billings, Skiba \& Connors, 2005; Dobbs et al. 2009; Tanner et al., 2004a, 2004b; Fish \& Snodgrass, 2014). There is a need to assess both the student and instructor's perspectives with respect to online education (Shieh, Gummer \& Niess, 2008). Information and knowledge regarding instructor beliefs are important to improving instructional effectiveness (Farrell \& Kun, 2009). The question before us is: How do instructors - those that have taught and those that have not taught online - perceive online education compared to face-to-face (FTF) education today? Our research aims to provide a timely answer to this question.

Other researchers have addressed aspects of this question in the past; however, the results of previous research provide mixed results. In 2004, faculty perceptions (at public and nonprofit private institutions in the United States) on the effectiveness of online instruction in terms of the seven principles of effective undergraduate education revealed that faculty rated online education slightly more effective overall and more effective for promoting prompt feedback, time on task, respect for diverse learning styles and communicating high expectations (Guidera, 2004). 
However, online education was rated less effective on promoting studentto-instructor contact and cooperation among students (Guidera, 2004). In another more recent study, instructors without online experience felt that online teaching would never be as effective as traditional classroom teaching (Fish \& Gill, 2009). The study reported instructor perceptions on teaching and learning outcomes as strongly influenced by experience teaching online as an instructor. Those with positive experiences felt that online and FTF instruction yielded equivalent outcomes, while those instructors with no online or negative experiences indicated that outcomes were not the same (Fish \& Gill, 2009). Over a decade ago, many instructors perceived online instruction as inferior to traditional teaching (Wilson, 2001), and instructors gravitated towards instructional practices that were most comfortable to them (Hinson \& LaPrairie, 2005). Over a decade ago, using the Delphi method, 36 business instructors from AACSB accredited universities who taught online were questioned on best practices in online education (Gallegos \& Butters, 2007). Results from the study highlighted the need for incentives to professors to teach online and need for professors to learn pedagogy respective to the online environment (Gallegos \& Butters, 2007). Similarly, in a 2009 survey of over 10,000 faculty members from close to 70 colleges and universities, most instructors felt that their institutions did not provide online support and incentives to teach online (Seaman, 2009). However, these surveys were conducted over 8 years ago as MOOCs and online education were just starting to explode.

A literature review reveals a number of factors that have been shown to impact instructors' perceptions of online education. These factors fall into three broad categories. There are demographic factors such as age, gender, major or discipline, level taught, faculty rank, and self-reported technological skill level. There are also individual (personal) factors such as motivation, discipline, self-directed learning and independence, time and cost investment, preference, happiness and appropriateness for learning environment, online orientation, and cultural differences. The third category includes program factors such as course organization, 
academic rigor (or difficulty), program quality, academic integrity (or cheating), instructor-to-instructor involvement and collegiality, studentto-instructor interaction, communication mechanisms, student-to-student interaction, and program technologies. Since the focus of this paper is on the program factors, we continue by summarizing the literature for program factors.

\section{Program Factors}

Program factors relate to the design of the courses and the activities included in the program design. In designing online courses, instructors tend to use FTF components that worked well, even when they do not believe they will work as well in the online environment (Connolly, Jones \& Jones, 2007). Correspondingly, instructors felt restricted or frustrated when teaching an online course they did not design (Richardson et al., 2016). Instructor's individual beliefs guide the strategies that they use to deliver web-based instruction (Wood, 2002). In developing online education, a critical transformation is the instructor's transformation from lecturer to facilitator (Kochtanek \& Hein, 2000).

Seven principles used in FTF education to deliver quality undergraduate education include student-to-instructor interaction, cooperation amongst students, encourage active learning, provide timely feedback, emphasize time on task, communicate high expectations and value diverse talents (Chickering \& Gamson, 1987). While these seven principles were not designed for online education, they can improve the online environment (Zhang \& Walls, 2006). With the seven principles in mind, along with our previous studies on student perceptions (Fish \& Snodgrass, 2016a, 2016b), our study sought to study the instructor's perceptions of program factors including: academic integrity, academic program rigor, academic program quality, communication mechanisms and course activities, course organization, student-to-instructor interaction, student-to-student interaction, and technical program activities. These factors cluster into three main areas of study: program attributes; communication among and between students and instructors; and program design and activities. 
In terms of program attributes, a literature search revealed few studies analyzing instructor perceptions on online academic integrity (or 'cheating'). Studies reveal that FTF and online students perceive that it is easier to cheat online than in the traditional classroom (Fish \& Snodgrass, 2014). At a public university in the southeast, instructors - particularly those without online experience, were concerned with student honesty, trust and security in the online teaching environment (Fish \& Gill, 2009). A recent study indicates that instructors still question the academic rigor associated with online teaching (Terosky \& Heasley, 2015). An older study indicates that some instructors perceive that the quality of online courses can be assessed by the amount of time students spend on the course, instead of the level of student engagement, student achievement, and learning objectives (Shieh et al., 2008).

Some research on communication issues exists. While in a traditional educational environment, verbal and nonverbal communication between the instructor and students assists instructors to modify and delivery content, communication in the online environment is more complex than in traditional instruction (Chang, Shen \& Liu, 2014). As for communication, many instructors view the feedback provided in the online medium as a 'communication strategy' as some instructors view their role in discussions as a means to communicate or to model their own teaching style (Richardson et al., 2016). Even when the instructor doesn't perceive the need for student-to-instructor communication, instructors agree that participation and engagement is key in the online environment (Richardson et al., 2016).

The support to an instructor by other instructors including involvement and collegiality has been the focus of a few recent studies. Typically, online instructor training is a one-time activity-focused course on the course management system, content-neutral and often lacks collaboration with other instructors (Terosky \& Heasley, 2015). Contrastingly, a study into faculty preference on instructor-to-instructor interaction highlights the critical importance of community and collegiality to instructors 
(Herman, 2012). In higher education, collaborative learning communities are not a common practice (Velez, 2009). While collegiality remains unsatisfactory at many campuses (Kezar, 2012), this is acutely apparent with online faculty who are physically separated from one another (Glass, 2012; Maier, 2012). Noteworthy to our study which was conducted at a private institution, private institutions are less likely to offer mentoring and peer collaborations than public institutions (Meyer \& Murrell, 2014).

A critical factor that has been studied by several researchers and impacts upon student learning and motivation to learn in an online environment is interaction (Anderson, 2006; Garrison \& Cleveland-Innes, 2005). Factors that increase interaction among students and between students and their instructors in online courses include group work, course environment, model use, community, discussion question type and assessment, feedback type and medium, immediacy behaviors, discourse guidelines, and instructor participation (York \& Richardson, 2012).

Key factors in online education include social presence (degree of connectedness to others felt by participants in an instructional environment), teaching presence (instructional methods used to develop and support valuable instructional experiences) and instructor presence (comprehensive concept including instructional design, instructor roles and styles, and specific behaviors and interactions) (Richardson et al., 2016). Online instructors play multiple roles of design/planning, social, instructive, technological and management (Guasch, Alvarez \& Espasa, 2010). Instructor presence, which is personal for both the student and instructor, is important in connecting with students through being approachable, showing them concern, and demonstrating expertise (Richardson et al., 2016). With respect to student-to-instructor interaction, the loss of FTF contact with students is a leading concern among online faculty (McQuiggan, 2012). However, another study indicates that instructors appeared to be less certain about the impact of instructor presence in student learning (Richardson et al., 2016). Instructors report that online teaching is more challenging than FTF teaching with respect 
to student-to-instructor interaction and student assessment (Connolly, Jones \& Jones, 2007). Students mainly want available instructors who are willing to provide timely feedback, listen to concerns and guide them (Vesely et al., 2007). In online professional development, instructors taking the courses indicate that the lack of face-to-face interaction is a critical barrier to online professional development. The interaction between instructors and students is essential to promote social, collaborative online learning (Hill, Raven \& Han, 2002; Swan, et al., 2000). Studies report that students appreciate online instructors who are responsive to their needs and provide clear course requirements and explanations (Sheridan \& Kelly, 2010). With respect to instructor interaction, 'being present' is a construct of instructor immediacy and includes demonstrating a sense of a unique person, expressing emotions, and relating appropriate responses to students (Schutt, Allen \& Kaumakis, 2009). Higher levels of social presence and psychological involvement encourage these factors to exist in education and include actions such as providing timely and active student feedback (Bailie, 2011). A construct associated with psychological involvement is authenticity, which includes the quality and extent of personal disclosure, both of which are related to cognitive and affective presence and interaction (Starr-Glass, 2011). Social presence and associated constructs positively impact upon distance learning environments and can increase participant activity and online interaction (Tu \& McIsaac, 2002).

In the online environment, instructors find encouraging student-tostudent interaction and cooperation is very difficult (Zhang \& Walls, 2006). How the instructor is 'present' through assuming different online roles and personas encourages and supports exchange amongst students (Starr-Glass, 2011). However, differences between instructor's cultures have been noted. For example, in the online environment, U.S. instructors indicated that learning styles and student-to-student interaction should be emphasized, while Korean educators indicated that student-to-instructor interaction was more important to learning (Yoo et al., 2014). This result can be attributed to U.S. instructors viewing their role as facilitators 
to enhance student interaction, while Korean instructors view their roles more traditionally as delivering knowledge to the student (Yoo et al., 2014).

With respect to course design and organization, insight into instructor's perceptions can be noted through the study on U.S. and Korean instructors perceptions, where both groups of instructors viewed good communication and well-organized courses as fundamental for successful online education (Yoo et al., 2014). In designing and delivering online education, instructors make decisions with respect to the activities that students will participate in and learn from. Available technology can reshape academic work as human relationships are vital to learning (Glass, 2012). In adding web-improved preparations for themselves and their students, instructors felt these contributed to greater student engagement and active classroom learning (Wingard, 2004). When teaching online, instructors make decisions on physical interactions (engagement of work), social bonds (engagement with others and the instructor), and explores the instructor's sense of self (Glass, 2012). The pedagogical features of major course management systems include collaboration and communication, content creation and delivery, administrative tools, assessment tools, and learning tools (Seok et al., 2010).

In the online environment, these activities can include discussion boards, in-class sessions, additional reading materials, homework, videos, instructor lectures, instructor chat sessions, interaction with other students, problem scaffolding and hints, textbooks, instructor posted notes, and surveys. At a public institution in the southeast, instructors with positive online experiences believed that lectures, case studies, group discussions, group activities and research could effectively be used in online education; however, instructors with negative online experiences did not believe that group discussions, group activities and research could be effectively used online (Fish \& Gill, 2009). Interestingly, instructors without online experience at all believed that lectures could be taught online as they viewed online classroom activities through 
a traditional lens (Fish \& Gill, 2009). Additionally, many instructors indicated that laboratory components and hands-on activities could not be implemented online (Fish \& Gill, 2009). In using discussion boards, some online instructors still question it as a critical activity (Terosky \& Heasley, 2015). Surveys can play a valuable part in social presence and initiating relational bridges with students as well as providing structure for student response and communication (Starr-Glass, 2011). Surveys typically are understood by students and can assist instructors in organizing and delivery the course, in-process adjustment and redesign, and convey strategies for cross-cultural sensitivity, diversity and inclusion (StarrGlass, 2011).

\section{Summary}

While not intended to be a comprehensive review of literature on instructor perceptions of online education, the literature review serves to outline the lack of research in this area. As noted above, most available research is over a decade old, when available technology and instructor understanding of online education was very different. Also, the few studies performed differ in size (small, medium, large universities), audience (e.g. scientific versus social sciences, business versus nonbusiness, and graduate versus undergraduate), and method of research (e.g. interview, survey). The context of the study may be an important factor to consider in interpretation of the survey results. As we noted in a similar study with respect to student perceptions (Fish \& Snodgrass, 2016a, 2016b), as technology changes, online education changes and perceptions change as well. As noted above, there are very few studies on program factors, and many that exist are over 10 years old.

We conducted our study at a mid-sized, Jesuit, Catholic, private school with a focus on teaching. The research focus lies in uncovering instructor perceptions that offers instruction in traditional arts and sciences, education and business and where FTF class sizes average 17 students. While online education is a growing educational method (Allen \& Seaman, 2013), not all faculty have been trained in or participated in 
online course development. Based upon the literature, the intent of this research is to explore instructors' perceptions of the online experience for those who have taught in and those who have never taught in the online environment. Specifically, this research seeks to explore: How do instructors that teach online compare to FTF instructor perceptions for course difficulty, cheating, student-to-student and student-to-instructor interaction? What are the activities that instructors choose to include in their online and FTF classes? Are they similar or different? Theoretically, instructors should perceive the environments equally and not favor either traditional or online education. As for activities, online course design experts indicate that the activities used online instead of in the traditional FTF classroom should be different and focus on creating interaction between people.

\section{PREVIEW COMPLETE}

This completes the limited preview of this paper. Please visit the link below to purchase.

\section{Citation Information}

Fish, Lynn A., and Coral R. Snograss. "Instructor Perspectives of Online versus Face-to-Face Education at a Jesuit Institution: Program Factors ." The BRC Academy fournal of Education 7, no. 1 (2018): 55-77. http:// dx.doi.org/10.15239/j.brcacadje.2018.07.01.ja03

\section{Web APPE NDix}

A web appendix for this paper is available at:

http://dx.doi.org/10.15239/j.brcacadje.2018.07.01.wa03 